\title{
Damage Induced by Helium Ion Irradiation in Fe-based Metallic Glass
}

\author{
Xiaonan Zhang, Xianxiu Mei ${ }^{1}$, Qi Zhang, Xiaona Li, Jianbing Qiang, Younian Wang \\ Key Laboratory of Materials Modification by Laser, Ion and Electron Beams, Dalian University of Technology, Ministry of Education,
} Dalian 116024, China

\begin{abstract}
The changes in structure and surface morphology of metallic glasses $\mathrm{Fe}_{80} \mathrm{Si}_{7.43} \mathrm{~B}_{12.57}$ and $\mathrm{Fe}_{68} \mathrm{Zr}_{7} \mathrm{~B}_{25}$ before and after the irradiation of $\mathrm{He}$ ions with the energy of $300 \mathrm{keV}$ were investigated, and were compared with that of the tungsten. The results show that after the $\mathrm{He}^{2+}$ irradiation, metallic glass $\mathrm{Fe}_{68} \mathrm{Zr}_{7} \mathrm{~B}_{25}$ still maintained amorphous. While a small amount of metastable $\beta$-Mn type phase nanocrystals formed in metallic glass $\mathrm{Fe}_{80} \mathrm{Si}_{7.43} \mathrm{~B}_{12.57}$ at the fluence of $4 \times 10^{17}$ ions $/ \mathrm{cm}^{2}(19 \mathrm{dpa})$. The nanocrystals transformed into $\alpha-\mathrm{Fe}$ phase and tetragonal $\mathrm{Fe} 2 \mathrm{~B}$ phase as the fluence increased to $1 \times 10^{18}$ ions $/ \mathrm{cm}^{2}(47 \mathrm{dpa})$. Then the new orthogonal $\mathrm{Fe}_{3} \mathrm{~B}$ phase and $\beta-\mathrm{Mn}$ type phase nanocrystals appeared when the fluence increased further, and the quantities of nanocrystals increased. Blisters and cracks appeared on the surface of tungsten under the irradiation fluence of $1 \times 10^{18}$ ions $/ \mathrm{cm}^{2}$, however only when the fluence was up to $1.6 \times 10^{18} \mathrm{ions} / \mathrm{cm}^{2}$, could cracks and spalling appear on the surfaces of metallic glasses.
\end{abstract}

Keywords: $\mathrm{He}^{2+}$ ion beam; irradiation damage; metallic glass; tungsten

\section{Introduction}

One of the most urgent problems in the future fusion reactors is the choice of irradiation resistant materials. The tungsten is considered to show a good irradiation resistance and can be applied to the future fusion reactors due to its excellent properties such as high melting point, good thermal conductivity, low thermal expansion coefficient, low physical sputtering rate, low tritium retention, etc.[1] However, long-term irradiation of thermal neutrons, hydrogen isotope particles, helium ions, impurity particles, etc. will result in damage such as blistering, swelling, cracking, etc. in tungsten [2]. And this damage will shorten the service life of the tungsten and cause pollution to the core plasma, thereby affecting the operation of the fusion reactors.

Structured by long-range disorder and short-range order, metallic glasses are thought to absorb the damage induced by irradiation due to their heavily disordered amorphous structure [3]. And because of their good physical and chemical properties such as high strength and excellent corrosion resistance, metallic glasses have attracted widespread attention from the researchers. Fe-based metallic glasses are supposed to be applied in the future fusion reactor irradiation

${ }^{1}$ Corresponding author: xxmei@dlut.edu.cn Tel \& Fax: +8641184708389 
environment due to their wide super-cooled liquid region, relatively high crystallization temperature, and a lack of neutron activation element. The researchers carried out some studies about the irradiation-induced damage in Fe-based metallic glasses: Umakoshi et al. used high energy electron to irradiate FeZrB metallic glass and discovered that $\alpha$-Fe phase nanocrystalline formed after the irradiation [4]; Rodriguez et al. observed recrystallization phenomenon in amorphous $\mathrm{Fe}_{80} \mathrm{~B}_{20}$ ribbons during the high energy $\mathrm{Au}$ ion irradiation experiments [5]; Rizza et al. explained the crystallization in the Fe-based metallic glasses after the irradiation of $\mathrm{Pb}$ ion with an energy of $5 \mathrm{GeV}$ by the relaxation of the high level of energy deposited in electronic excitations along the path of ions [6]; Kane et al. found that after the electron irradiation, the width of the first coordination shell of Fe atoms decreased and the amorphous matrix was transforming to more ordered phase in metallic glass FeSiBNb [7]; Sun et al. irradiated amorphous FeSiNbZrB ribbons with 5MeV Xe ions and discovered that after irradiation, the number of nanocrystalline increased with the increase of irradiation fluences, but the size of nanocrystalline saturated as the ion fluences increased [8]. As the potential candidates of irradiation resistant materials in the fusion reactors, Fe-based metallic glasses need to sustain the bombardment of thermal neutrons, hydrogen isotope particles, helium ash, sputtering impurity atoms and high heat load. Therein, helium ion irradiation can induce the formation of helium bubbles, causing performance deterioration to the materials.

At present, the crystallization behavior induced by the helium ion irradiation in Fe-based metallic glasses is not clear. In this study, we used $\mathrm{He}^{2+}$ ions with the energy of $300 \mathrm{keV}$ to irradiate metallic glasses $\mathrm{Fe}_{80} \mathrm{Si}_{7.43} \mathrm{~B}_{12.57}$ and $\mathrm{Fe}_{68} \mathrm{Zr}_{7} \mathrm{~B}_{25}$ as well as tungsten to investigate the crystallization behavior and surface damage caused by the irradiation in the two metallic glasses, and employed tungsten as a comparison to provide the reference of possibility which the metallic glasses applied in the future fusion reactor irradiation environment.

\section{Experimental methods}

The metallic glass ribbons $\mathrm{Fe}_{80} \mathrm{Si}_{7.43} \mathrm{~B}_{12.57}$ and $\mathrm{Fe}_{68} \mathrm{Zr}_{7} \mathrm{~B}_{25}$ used in this study were prepared by melt-quench method. The thickness of metallic glass $\mathrm{Fe}_{80} \mathrm{Si}_{7.43} \mathrm{~B}_{12.57}$ and $\mathrm{Fe}_{68} \mathrm{Zr}_{7} \mathrm{~B}_{25}$ is $35 \mathrm{um}$ and 40um, respectively. Metal W used in this study had a purity of $99.95 \%$ with the size of $5 \mathrm{~mm} \times 5$ $\mathrm{mm} \times 2 \mathrm{~mm}$. Surfaces of tungstens were mechanically polished to a mirror finish and then all the samples cleaned ultrasonically with acetone and alcohol prior to the irradiation experiment. The ion beam irradiation experiment was completed on the $320 \mathrm{kV}$ highly charged ion research platform at Institute of modern physics, Chinese academy of sciences. The samples were irradiated with $\mathrm{He}^{2+}$ ions of $300 \mathrm{keV}$ energy with fluences of $1 \times 10^{17}$ ions $/ \mathrm{cm}^{2}, 2 \times 10^{17}$ ions $/ \mathrm{cm}^{2}, 4 \times 10^{17}$ ions $/ \mathrm{cm}^{2}$, $1 \times 10^{18}$ ions $/ \mathrm{cm}^{2}$ and $1.6 \times 10^{18}$ ions $/ \mathrm{cm}^{2}$. To avoid the effect of irradiation ions flux on the material behavior[9,10], the flux for all the samples was $1.2 \times 10^{13}$ ions $/ \mathrm{cm}^{2} \mathrm{~s}$.

The phase structure of the unirradiated and irradiated samples was studied by X-ray diffraction 
(XRD) with $\mathrm{Cu} \mathrm{K} \alpha$ radiation, and the changes on microstructure of samples were analysed by transmission electron microscope (TEM) with the operating voltage of $200 \mathrm{kV}$. The samples for TEM were prepared by focused ion beam (FIB) method. The surface morphology was characterized by scanning electron microscope (SEM). In addition, the ion range, concentration distribution of He atoms and DPA value in the metallic glasses and metal W were calculated by SRIM programme.

\section{Results and discussion}

\subsection{Evolution of $\mathrm{Fe}_{80} \mathrm{Si}_{7.43} \mathrm{~B}_{12.57}$ metallic glass microstructure under irradiation}

Fig. 1 shows the GID-XRD patterns of metallic glasses $\mathrm{Fe}_{80} \mathrm{Si} 7.43 \mathrm{~B}_{12.57}$ before and after the $\mathrm{He}$ ion irradiation. It can be seen that the pattern of sample before irradiation presented broad peak, which demonstrated amorphous state of the original sample. After irradiation, no sharp diffraction peak appeared in the patterns of metallic glasses, which indicated that $\mathrm{Fe}_{80} \mathrm{Si}_{7.43} \mathrm{~B}_{12.57 \text { metallic }}$ glasses remained amorphous state as the main phase structure.

The cross-section TEM image and the corresponding SAED pattern of unirradiated metallic glass $\mathrm{Fe}_{80} \mathrm{Si}_{1743} \mathrm{~B}_{12.57}$ are shown in Fig.2. From Fig.2(a), it can be seen that no obvious damage was induced by $\mathrm{Ga}$ ions irradiation. And there was only one halo in the Fig.2(b) indicating that the sample prepared by FIB technology was amorphous. That is, for metallic glass $\mathrm{Fe}_{80} \mathrm{Si}_{7.43} \mathrm{~B}_{12.57}$, preparation of TEM sample by FIB method would not cause crystallization.

The cross-section TEM image of metallic glass $\mathrm{Fe}_{80} \mathrm{Si}_{7.43} \mathrm{~B}_{12.57}$ after the irradiation at a fluence of $4 \times 10^{17}$ ions $/ \mathrm{cm}^{2}$ (19dpa) is given in Fig.3(a). A white belt with a width of about $250 \mathrm{~nm}$ formed about 700nm away form the surface, namely a helium bubble layer. Similar helium bubbles had also been observed by Iwakiri et al [11] and Zhan et al [12]. Fig.3(b) and (c) show the selected-area electron diffraction images of regions A and B in Fig.3(a), respectively. Only one halo can be observed in Fig.3(b). It is illustrated that the metallic glass is still maintained amorphous in region A, the area which ions passed through. In Fig.3(c), another two halos appeared, which shows that the nanocrystalline formed in region $\mathrm{B}$, the area with helium bubble layer, and the two halos corresponded to (211) and (411) crystal planes of $\beta$-Mn type phase. Fig.3(d) gives the selected-area electron diffraction image of region $\mathrm{C}$ in Fig.3(a). It showed that only one halo, so it proved that the crystallization in region B of Fig.3(a) was cause by He ions irradiation rather than the overthinned during the FIB preparation.

Fig.4 presents the HRTEM images and the corresponding fast Fourier transform (FFT) patterns of different crystallization areas in helium bubble layer of metallic glass $\mathrm{Fe}_{80} \mathrm{Si}_{7.43} \mathrm{~B}_{12.57}$ after irradiation at a fluence of $4 \times 10^{17}$ ions $/ \mathrm{cm}^{2}$. It can be observed that tiny and isolated $\beta$-Mn type phase nanocrystals formed in helium bubble layer when the fluence of $\mathrm{He}$ ions was $4 \times 10^{17}$ ions $/ \mathrm{cm}^{2}$ (19dpa). 
Fig.5 shows the cross-section TEM image of metallic glass $\mathrm{Fe}_{80} \mathrm{Si}_{7.43} \mathrm{~B}_{12.57}$ after the irradiation at a fluence of $1 \times 10^{18}$ ions $/ \mathrm{cm}^{2}(47 \mathrm{dpa})$. It can be seen that a helium bubble layer formed $690 \mathrm{~nm}$ to $980 \mathrm{~nm}$ away fromthe surface. Larger holes with the length of about $100 \mathrm{~nm}$ in the Figure were induced by peeling of thin areas when focused ion beam was used to cut samples. The selected-area electron diffraction images of regions A and B in Fig.5(a) are presented in Fig.5(b) and (c), respectively. Only one halo appeared in Fig.5(b), indicating that the metallic glass was maintained amorphous in the area which ions passed through. In Fig.5(c), the number of halos increased, and some diffraction spots distributed on the halos. It is demonstrated that $\alpha-\mathrm{Fe}$ phase and $\mathrm{Fe}_{2} \mathrm{~B}$ phase formed in region B, the helium bubble layer. Fig. 6 gives the HRTEM images and the corresponding fast Fourier transform (FFT) patterns of the two phases. It exhibited that a small amount of isolated $\alpha$-Fe phase and tetragonal $\mathrm{Fe}_{2} \mathrm{~B}$ phase nanocrystals generated in helium bubble layer under the irradiation.

Fig.7 presents the cross-section TEM image and the corresponding selected area electron diffraction images of metallic glass $\mathrm{Fe}_{80} \mathrm{Si}_{7.43} \mathrm{~B}_{12.57}$ under the irradiation at a fluence of $1.6 \times 10^{18}$ ions $/ \mathrm{cm}^{2}$ (76dpa). As can be seen from Fig.7(a), similar to Fig. 5(a), a helium bubble layer formed $650 \mathrm{~nm}$ and $1000 \mathrm{~nm}$ away from the surface, which is consistent with the concentration distribution of He atoms with the depth calculated by SRIM program. In the Figure, larger holes with the length of about $100 \mathrm{~nm}$ were also induced by peeling of thin areas during the preparation of TEM samples. After the irradiation, region A, the He ions passed through, remained amorphous, which is demonstrated by the observation of only one halo in Fig.7(b). While in Fig.7(c), the halos and diffraction spots proved that crystallization occurred in the helium bubble layer. Compared with Fig.5(c), the number of halos and diffraction spots in Fig.7(c) increased, which indicated that with the increase of irradiation fluence, the number of nanocrystalline phases and the volume fraction of crystalline phase increased.

The HRTEM images and the corresponding fast Fourier transform (FFT) patterns of different crystallization areas in helium bubble layer of metallic glass $\mathrm{Fe}_{80} \mathrm{Si} \mathrm{S}_{.43} \mathrm{~B}_{12.57}$ under irradiation at a fluence of $1.6 \times 10^{18} \mathrm{ions} / \mathrm{cm}^{2}$ (76dpa) are shown in Fig.8(a)-(f). When the flunece increased to $1.6 \times 10^{18}$ ions $/ \mathrm{cm}^{2}(76 \mathrm{dpa})$, the nanocrystals formed in helium bubble layers still included $\alpha$-Fe phase and $\mathrm{Fe}_{2} \mathrm{~B}$ phase, as shown in regions $\mathrm{A}$ and $\mathrm{C}$ of Fig.8(a), $\beta$-Mn type phase and orthogonal $\mathrm{Fe}_{3} \mathrm{~B}$ phase nanocrystals also appeared, as shown in region B of Fig.8(a) and white box area of Fig.8(e), respectively. The distribution of composition with depth in metallic glass $\mathrm{Fe}_{80} \mathrm{Si}_{7.43 \mathrm{~B}_{12.57} \text { is }}$ presented in Fig.8(g). It can be observed that the distribution of composition is uneven. This is one of the reasons for crystallization in the metallic glass. Ion irradiation is a process of energy injection. Frank-Kasper coordination polyhedra exist in the metallic glass as local structures. Their transformation into the $\beta$-Mn type metastable crystalline phases was only based on a short-range 
atomic diffusion process [13], which was driven by the injected energy of irradiation. Therefore, $\beta$-Mn type phase formed under the irradiation at a fluence of $4 \times 10^{17}$ ions $/ \mathrm{cm}^{2}$ (19dpa). When the fluence increased to $1 \times 10^{18}$ ions $/ \mathrm{cm}^{2}$ (47dpa), $\beta$-Mn type phase transformed into stable $\alpha$-Fe and $\mathrm{Fe}_{2} \mathrm{~B}$ phases with lower activation energies. In the studies of Umakoshi et al. [4] and Rizza et al. [6], similar crystalline phases such as $\alpha$-Fe phase and $\mathrm{Fe}_{2} \mathrm{~B}$ phase formed in Fe-based metallic glasses after the irradiation. In lots of annealing studies, the order of crystalline phase appeared in Fe-based metallic glasses is metastable $\alpha / \beta-\mathrm{Mn}$ type and $\mathrm{Fe}_{23} \mathrm{~B}_{6}$ phases $\rightarrow \alpha-\mathrm{Fe}$ phase $\rightarrow$ metastable $\mathrm{Fe}_{3} \mathrm{~B}$ phase $\rightarrow$ stable $\alpha-\mathrm{Fe}$ and $\mathrm{Fe}_{2} \mathrm{~B}$ phases [14-16]. However, in this study, metastable $\beta$-Mn type and orthogonal $\mathrm{Fe}_{3} \mathrm{~B}$ phases still existed even under the irradiation at the maximum fluence $\left(1.6 \times 10^{18}\right.$ ions $\left./ \mathrm{cm}^{2}, 76 \mathrm{dpa}\right)$. This is due to the fact that ion irradiation is such a non-equilibrium process of energy injection that the energy carried by incident ions dissipate fast in the amorphous matrix, and there is no enough time for target atoms to relax to the steady state. Therefore, metastable phases still exist.

Fig.9 shows the HRTEM image of helium bubble layer in metallic glass Fe80Si7.43B12.57 after the irradiation at different fluences. When the fluence increased was $4 \times 10^{17}$ ions $/ \mathrm{cm}^{2}$ (19dpa), the most popular diameters of helium bubbles were less than $5 \mathrm{~nm}$. And the average sizes of helium bubbles increased significantly with the fluences incerased form $4 \times 10^{17} \mathrm{ions} / \mathrm{cm}^{2}$ (19dpa) to $1 \times 10^{18}$ ions $/ \mathrm{cm}^{2}$ (47dpa). When the fluence increased further to $1.6 \times 10^{18}$ ions $/ \mathrm{cm}^{2}$ (76dpa), helium bubbles grew slowly. This is related to the increase in quantity of nanocrystals at this fluence. The augment of the nanocrystals would induce the formation of stress field in metallic glasses, and the stress field would hinder the diffusion of He ions, thereby inhibiting the growth of helium bubbles [17]. After the irradiation, the diameters of most of helium bubbles were less than $5 \mathrm{~nm}$, and the bubbles were still in the early stages of nucleation and growth. When the irradiation fluence was $1.6 \times 10^{18}$ ions $/ \mathrm{cm}^{2}$ (76dpa), several bubbles with the diameter of more than $20 \mathrm{~nm}$ appeared, and the greatest diameter was up to $20.9 \mathrm{~nm}$.

The TEM images of under-focus and over-focus of helium bubble layer in metallic glass Fe80Si7.43B 12.57 after the irradiation are given in Fig.10(a) and (b). Bubbles presented bright Fresnel fringes in Fig.10(a), while presented dark Fresnel fringes in Fig.10(b). This phase contrast demonstrated that the round defects distributed $600 \mathrm{~nm}$ to $1000 \mathrm{~nm}$ away from the surfaces of samples in Fig.3(a), 5(a) and 7(a) were bubbles indeed [18]. Fig.10(c) shows the HRTEM image of connection and growth of helium bubbles. This growth of helium bubbles is caused by attraction and merging among small bubbles and Ostwald ripening [19]. "Vacancy-like" and "interstitial-like" damage would generate in metallic glass $\mathrm{Fe}_{80} \mathrm{Si}_{7.43} \mathrm{~B}_{12.57}$ during the injection of $\mathrm{He}$ ions, and the energy deposition induced by ion implantation increased the atomic diffusion rate in the metallic glass, which made "vacancy-like" damage recombine with He atoms to form helium bubbles. 
Interattraction, connection and merger made small bubbles grow into large bubbles, which would swallow small bubbles to continue to grow, in order to reduce the surface curvature, thereby reducing the surface energy to achieve a more stable state. The observed phenomenon of connection and growth of helium bubbles is consistent with the result of Fig.9 that the large bubbles formed. In our previous studies, similar growth of bubbles had been observed in Zr-based metallic glass under $500 \mathrm{keV} \mathrm{He}^{2+}$ ion irradiation [20] and Fe-based metallic glass irradiated by $40 \mathrm{keV}$ proton [9].

Fig.10(d) shows the HRTEM image of crystallization in helium bubble layer of metallic glass $\mathrm{Fe}_{80} \mathrm{Si}_{7.43} \mathrm{~B}_{12.57}$. Under the irradiation of He ions, crystallization phases mainly existed in the helium bubble layer, and no crystallization occurred in the area which ions passed through. This is mainly due to the existence of excess free volume in the helium bubble layer induced by irradiation.The free volume promoted the formation of the helium bubbles, and also provided effective nucleation points for crystalline phase [21]. Moreover, the free volume increased the diffusion rate of atoms and promoted the crystallization. During the formation of helium bubbles, close packing of target atoms would occur around bubbles to balance the pressure inside the bubbles, as shown in Fig.10(d), the area near the outline of bubbles is dark, where the increase of atomic density also contributed to the crystallization. In addition, the retention of He atoms led to uneven distribution of composition

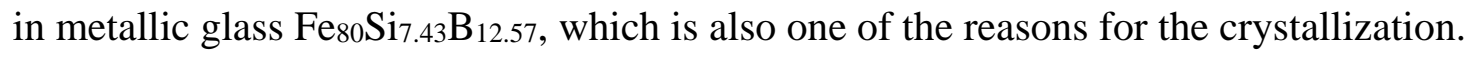

\subsection{Evolution of $\mathrm{Fe}_{68} \mathrm{Zr}_{7} \mathrm{~B}_{25}$ metallic glass microstructure under irradiation}

Fig.11 shows the GID-XRD patterns of metallic glasses $\mathrm{Fe}_{68} \mathrm{Zr}_{7} \mathrm{~B}_{25}$ before and after the He ions irradiation with different fluences. It can be seen that after irradiation, $\mathrm{Fe}_{68} \mathrm{Zr}_{7} \mathrm{~B}_{25}$ metallic glasses remained amorphous state as the main phase structure which demonstrated by broad peaks.

The cross-section TEM image and the corresponding SAED patterns of metallic glass $\mathrm{Fe}_{68} \mathrm{Zr}_{7} \mathrm{~B}_{25}$ after the irradiation at a fluence of $1.6 \times 10^{18}$ ions $/ \mathrm{cm}^{2}(68 \mathrm{dpa})$ are shown in Fig. 12. Fig.12(a) exhibits that a bubble layer with a thickness of about $300 \mathrm{~nm}$ formed $650 \mathrm{~nm}$ to $950 \mathrm{~nm}$ away from the surface, which is consistent with the concentration distribution of He atoms with the depth calculated by SRIM program. The SAED patterns of regions A and B in Fig.12(a) are presented in Fig.12(b) and (c), respectively. It can be seen that there was only one halo in both figures, indicating that the metallic glass maintained amorphous after the irradiation.

Fig.13(a) and (b) shows the under-focused and the over-focused TEM image of helium bubble layer in the metallic glass $\mathrm{Fe}_{6} \mathrm{Z}_{7} \mathrm{r}_{7} \mathrm{~B}_{25}$. Bubbles exhibited bright Fresnel fringes in Fig.13(a), while exhibited dark Fresnel fringes in Fig.13(b). This indicated the existence of helium bubble layer.

Under the irradiation of He ions, a series of crystallization behaviors occurred in metallic glass Fe80Si7.43 $\mathrm{B}_{12.57}$, while metallic glass $\mathrm{Fe}_{68} \mathrm{Zr}_{7} \mathrm{~B}_{25}$ was still maintained amorphous. The differences between changes in phase structures of the two kinds of metallic glasses are mainly caused by the following three points: (1) The crystallization of metallic glasses depends on their composition. 
Inoue experience principle points out that the great atomic size ratios of main constituent elements would contribute to improve the glass forming ability (GFA) of metallic glasses [22]. The differences among the atomic radius in metallic glass $\mathrm{Fe}_{68} \mathrm{Zr}_{7} \mathrm{~B}_{25}$ are greater than those in metallic glass $\mathrm{Fe}_{80} \mathrm{Si}_{7.43} \mathrm{~B}_{12.57}$. Moreover, the increase in the content of $\mathrm{B}$ element can improve the glass forming ability of metallic glasses and make them have better amorphous stability [23]. These make $\mathrm{Fe}_{68} \mathrm{Zr}_{7} \mathrm{~B}_{25}$ have better resistance to crystallization. (2) The thermal effect induced by ion irradiation is also one of the causes of crystallization. The initial crystallization temperature $\left(\mathrm{T}_{\mathrm{x}}\right)$ of metallic glass $\mathrm{Fe}_{80} \mathrm{Si}_{7.43} \mathrm{~B}_{12.57}$ is $779 \mathrm{k}$, the glass transition temperature and the width of supercooled liquid can't be measured accurately due to the fact that metallic glass $\mathrm{Fe}_{80} \mathrm{Si}_{7.43} \mathrm{~B}_{12.57}$ is unstable. While metallic glass $\mathrm{Fe}_{68} \mathrm{Zr}_{7} \mathrm{~B}_{25}$ is stable and has higher initial crystallization temperature $\left(\mathrm{T}_{\mathrm{x}}=934 \mathrm{k}\right)$ and wide super-cooled liquid region $(\Delta \mathrm{T}=48 \mathrm{k})$ [4]. By comparison of the initial crystallization temperatures of both metallic glasses, it is clear that metallic glass $\mathrm{Fe}_{68} \mathrm{Zr}_{7} \mathrm{~B}_{25}$ with higher initial crystallization temperature has better resistance to crystallization. Thus, metallic glass $\mathrm{Fe}_{68} \mathrm{Zr}_{7} \mathrm{~B}_{25}$ can maintain amorphous under the irradiation at the fluence of $1.6 \times 10^{18}$ ions $/ \mathrm{cm}^{2}$ (68dpa). (3) According to the simulation results of SRIM programme, the DPA values in metallic glass $\mathrm{Fe}_{68} \mathrm{Zr}_{7} \mathrm{~B}_{25}$ and $\mathrm{Fe}_{80} \mathrm{Si}_{7.43} \mathrm{~B}_{12.57}$ under $300 \mathrm{keV}$ He ions irradiation were 68 and 76, respectively. This indicated that the irradiation-induced damage in the latter was more serious. And the damage induced by irradiation could increase the mobility of atoms in metallic glasses [24], which also contributed to the crystallization.

\subsection{Evolution of Fe-based metallic glass and tungsten surface morphology under}

\section{irradiation}

Fig.14(a0), (bo) and (co) show the SEM images of pristine metallic glasses $\mathrm{Fe}_{80} \mathrm{Si}_{7.43} \mathrm{~B}_{12.57}$ and $\mathrm{Fe}_{68} \mathrm{Zr}_{7} \mathrm{~B}_{25}$ as well as metal tungsten, respectively. The surfaces are essentially featureless except that only a small quantity of shear bands existed on the surface of metallic glass $\mathrm{Fe}_{80} \mathrm{Si}_{7.43} \mathrm{~B}_{12.57 \text {. The }}$ SEM images of metallic glasses $\mathrm{Fe}_{80} \mathrm{Si}_{7.43} \mathrm{~B}_{12.57}$ and $\mathrm{Fe}_{68} \mathrm{Zr}_{7} \mathrm{~B}_{25}$ after the irradiation are given in Fig.14(a $\left.a_{1}\right)-\left(a_{3}\right)$ and $\left(b_{1}\right)-\left(b_{3}\right)$. It can be observed that the surface of metallic glass $\mathrm{Fe}_{80} \mathrm{Si}_{7.43} \mathrm{~B}_{12.57} \mathrm{kept}$ smooth and the number of shear bands increased, while the surface of metallic glass $\mathrm{Fe}_{68} \mathrm{Zr}_{7} \mathrm{~B}_{25}$ maintained smooth, and no obvious damage could be observed until the fluence was up to $1 \times 10^{18}$ ions $/ \mathrm{cm}^{2}$. However, at the fluence of $1 \times 10^{18}$ ions $/ \mathrm{cm}^{2}$, a large area of blister and a small amount of spalling appeared on the surface of tungsten, as shown in Fig.14( $\left.\mathrm{c}_{2}\right)$. When the irradiation fluence further increased to $1.6 \times 10^{18}$ ions $/ \mathrm{cm}^{2}$, cracking and spalling occurred on the surface of metallic glass Fe $80 \mathrm{Si} 7.43 \mathrm{~B}_{12.57}$, as shown in Fig.14(a3), delamination and spalling appeared on the surface of metallic glass $\mathrm{Fe}_{68} \mathrm{Zr}_{7} \mathrm{~B}_{25}$, as shown in Fig.14(b3), and blisters grew up and damage area enlarged on the surface of the tungsten, as shown in Fig.14( $\left.c_{3}\right)$. This indicated that the 
irradiation resistances to $\mathrm{He}$ ions of both the Fe-based metallic glasses are better than that of the tungsten.

Metallic glasses possess long-range disordered structure and lack of dislocations, grain boundaries [25], stacking faults and other defects which exist in crystalline materials, thus they can avoid the occurrence of preferred orientation sputtering during the irradiation. The atoms in metallic glasses distribute disorderly, and for the metallic glasses, a plenty of free volume existed in them, the excess free volume promoted the diffuse of He atoms. During the He ions irradiation, when the incident $\mathrm{He}$ atoms reached a certain concentration, the widely distributing free volume provided nucleate site for the formation of He bubbles. This makes the solubility (The solubility was characterized by the fluence value which made the surface of material broken during the irradition) of He atoms in metallic glasses relatively high, therefore the surfaces of both the Fe-based metallic glasses maintained smooth even when the irradiation fluence increased to $1 \times 10^{18}$ ions $/ \mathrm{cm}^{2}$. The fluence further increased as the concentration of $\mathrm{He}$ atoms exceeded the threshold which the metallic glasses can dissolve, damage such as cracks, delaminations and spalling appeared on the surfaces of the metallic glasses. While the defects such as grain boundaries, vacancies and dislocations existing in tungsten can capture He atoms and make them accumulate then bubbles form. The formation of helium bubbles makes lattice distortion occur in tungsten and generate stress among the lattices. The stress could be released only through the surface deformation, which led to the appearance of delamination and spalling on the surface of tungsten.

Fig.15(a) presents the SEM image of shear steps in the exfoliation on the surface of metallic glass $\mathrm{Fe}_{80} \mathrm{Si}_{7.43} \mathrm{~B}_{12.57}$. Because of the good tenacity of metallic glass $\mathrm{Fe} 80 \mathrm{Si}_{7.43} \mathrm{~B}_{12.57 \text {, shear }}$ transformation occurred in the surface area with a small amount of free volume in the metallic glasses with the increase of fluences and the prolonged injection of ion energy during the ion irradiation. Due to effect of "ion hammering" [8], compressive stress would be generated in the direction perpendicular to the surface of sample during the injection of $\mathrm{He}$ ions. When the compressive stress applied was strong enough, shear transition zone would become very compact, thus a dense ductile shear zone formed and the shear stages appeared. Fig.15(b) shows the exfoliation on the surface of metallic glass $\mathrm{Fe}_{68} \mathrm{Zr}_{7} \mathrm{~B}_{25}$ after ion irradiation. Cracks and spalling also occurred on the surface of metallic glass $\mathrm{Fe}_{68} \mathrm{Zr}_{7} \mathrm{~B}_{25}$ during the irradiation. Because of the brittleness of metallic glass $\mathrm{Fe}_{68} \mathrm{Zr}_{7} \mathrm{~B}_{25}$, fracture morphology was presented in the exfoliation.

Under the irradiation of He ions with an energy of $300 \mathrm{keV}$, a series of crystallization processes occurred in metallic glass $\mathrm{Fe}_{80} \mathrm{Si}_{7.43} \mathrm{~B}_{12.57}$ : a small amount of metastable $\beta$-Mn type phase nanocrystals appeared in metallic glass $\mathrm{Fe}_{80} \mathrm{Si}_{7.43} \mathrm{~B}_{12.57}$ when the fluence was $4 \times 10^{17}$ ions $/ \mathrm{cm}^{2}$ (19dpa). When the fluence increased to $1 \times 10^{18}$ ions $/ \mathrm{cm}^{2}$ (47dpa), the $\beta$-Mn type phase nanocrystals transformed into $\alpha$-Fe phase and $\mathrm{Fe}_{2} \mathrm{~B}$ phase nanocrystals. In addition to the $\alpha$-Fe and $\mathrm{Fe}_{2} \mathrm{~B}$ phases, 
$\beta$-Mn type phase and $\mathrm{Fe}_{3} \mathrm{~B}$ phase nonacrystals formed and the volume fraction of crystalline phase increased in metallic glass $\mathrm{Fe}_{80} \mathrm{Si}_{7.43} \mathrm{~B}_{12.57}$ (76dpa) when the fluence was up to $1.6 \times 10^{18}$ ions $/ \mathrm{cm}^{2}$, while metallic glass $\mathrm{Fe}_{68} \mathrm{Zr}_{7} \mathrm{~B}_{25}$ (68dpa) maintained amorphous. This is mainly caused by the differences in atomic compositions and crystallization temperatures between the two kinds of Fe-based metallic glasses. Spalling appeared on the surfaces of both the metallic glasses when the irradiation fluence was $1.6 \times 10^{18}$ ions $/ \mathrm{cm}^{2}$, metallic glass $\mathrm{Fe}_{80} \mathrm{Si}_{7.43} \mathrm{~B}_{12.57}$ exhibited ductile shear steps, while metallic glass $\mathrm{Fe}_{68} \mathrm{Zr}_{7} \mathrm{~B}_{25}$ exhibited brittle fracture morphology. However, blisters and cracks appeared on the surface of tungsten at the fluence of $1 \times 10^{18}$ ions $/ \mathrm{cm}^{2}$. This is due to the fact that the energy deposition induced by He ions irradiation made displacement of target atoms happen, which produced a large number of defects (such as interstitial clusters, helium bubbles, dislocation loops, etc.) in tungsten. A lots of vacancies combined with He atoms, then they grew up by absorbing $\mathrm{He}$ atoms and vacancies to form $\mathrm{He}-\mathrm{V}$ compounds. This resulted in the lattice distortion and the blister on the surface. He ions irradiated sostenuto, which made the pressure inside the bubble increase. When the pressure was great enough to exceed the yield strength of tungsten surface, the surface finally ruptured. While the atoms in the metallic glasses were distributed disorderly, the incident $\mathrm{He}$ atoms had certain solubility in metallic glasses, thus spalling didn't occurr on the surface of the Fe-based metallic glasses until the irradiation fluence further increased to $1.6 \times 10^{18}$ ions $/ \mathrm{cm}^{2}$. Hence, the irradiation resistance to $\mathrm{He}^{2+}$ of $\mathrm{Fe}$-based metallic glasses are better than that of tungsten.

\section{Conclusion}

In metallic glass $\mathrm{Fe}_{80} \mathrm{Si}_{7.43} \mathrm{~B}_{12.57}$, when the fluence of $\mathrm{He}$ ions was up to $4 \times 10^{17}$ ions $/ \mathrm{cm}^{2}$ (19dpa), crystallization occurred, and a small amount of metastable $\beta$-Mn type phase nanocrystals formed. When the fluence increased to $1 \times 10^{18} \mathrm{ions} / \mathrm{cm}^{2}(47 \mathrm{dpa})$, the quantity of nanocrystals increased and metastable $\beta$-Mn type phase transformed into $\alpha$-Fe phase and tetragonal $\mathrm{Fe}_{2} \mathrm{~B}$ phase. Then orthogonal $\mathrm{Fe}_{3} \mathrm{~B}$ phase and $\beta$-Mn type phase formed and were added to the nanocrystals as the fluence increased to $1.6 \times 10^{18}$ ions $/ \mathrm{cm}^{2}(76 \mathrm{dpa})$, while metallic glass $\mathrm{Fe}_{68} \mathrm{Zr}_{7} \mathrm{~B}_{25}$ maintained amorphous under the He ion irradiation, till the fluence was up to $1.6 \times 10^{18}$ ions $/ \mathrm{cm}^{2}$ (68dpa). This indicates that the irradiation resistance of $\mathrm{Fe}_{68} \mathrm{Zr}_{7} \mathrm{~B}_{25}$ is better. After the irradiation, different damage morphologies were exhibited on the surfaces of the two kinds of Fe-based metallic glasses. When the fluence was $1.6 \times 10^{18}$ ions $/ \mathrm{cm}^{2}$, cracks and ductile shear steps appeared on the surface of metallic glass $\mathrm{Fe}_{80} \mathrm{Si}_{7.43} \mathrm{~B}_{12.57}$, and spalling as well as brittle fracture morphology appeared on the surface of metallic glass $\mathrm{Fe}_{68} \mathrm{Zr}_{7} \mathrm{~B}_{25}$. However, blisters and spallings occured on the surface of tungsten at the irradiation fluence of $1 \times 10^{18}$ ions $/ \mathrm{cm}^{2}$, and with the increase of irradiation fluence, the spalling phenomenon became more serious. Thus the irradiation resistance of Fe-based metallic glasses is better than that of tungsten. 


\section{Acknowledgements}

This work is financially supported by the National Science Foundation of China (No. 11375037 and No.11675035) and the National Basic Research Program of China (No. 2010CB832901). The experimental work was carried out at the $320 \mathrm{kV}$ platforms for multi-discipline research with highly charged ions at the Institute of Modern Physics, CAS.

\section{References}

[1] Y. Noiri, S. Kajita, N. Ohno, J. Nucl. Mater. 463 (2015) 285-288

[2] A. Suslova, O. El-Atwani, S.S. Harilal, A. Hassanein, Nucl. Fusion. 55 (2015) 033007 (15pp)

[3] S. Thomas, H.Thomas, D. K. Avasthi, A. Tripathi, R. V. Ramanujan, M. R. Anantharaman, J. Appl. Phys. 105 (2009) 033910

[4] T. Nagase, A. Nino, Y. Umakoshi, Mater. Trans. 48 (2007) 1340- 1349

[5] M.D. Rodriguez, B. Afra, C. Trautmann, N. Kirby, P. Kluth, Micro. Engn. 102 (2013) 64-66

[6] G. Rizza, A. Dunlop, G. Jaskierowicz, M. Kopcewicz, Nucl. Instrum. Methods Phys. Res., Sect. B 226 (2004) 609-621

[7] S.N. Kane, M. Satalkar, A. Ghosh, M. Shah, N. Ghodke, R. Pramod, A.K. Sinha, M.N. Singh, J. Alloy. Compd. 615 (2014) S324-S327

[8] J.R. Sun, Z.G. Wang, Y.Y. Wang, H.L. Chang, P. Song, T.L. Shen, Y.B. Zhu, L.L. Pang, F.S. Li, Nucl. Instrum. Methods Phys. Res., Sect. B 307 (2013) 486-490

[9] H.R. Zhang, X.X. Mei, X.N. Zhang, X.N. Li, Y.M. Wang, J.R. Sun, Y.N. Wang, Nucl. Instrum. Methods Phys. Res., Sect. B 375 (2016) 79-86

[10] H.R. Zhang, X.X. Mei, Y.M. Wang, Z.G. wang, Y.N. wang, J. Nucl. Mater.456 (2015) 344-350

[11] H. Iwakiri, K. Yasunaga, K. Morishita, N. Yoshida, J. Nucl. Mater. 283-287 (2000) 1134-1138

[12] P.P. Liu, Q. Zhan, Z.Y. Fu, Y.P. Wei, Y.M.Wang, F.M.Wang, S. Ohnuki, F.R.Wan, J. Alloy. Compd. 649 (2015) 859-864

[13] M. Ohnuma, O. Sasaki, H. Kuwano, S. Katano, Y. Morii, S. Funahashi, H.R.Child, Y. Hamaguchi, Mater. T. JIM. 34 (1993) 874- 881

[14] J.Y. Bang, R.Y. Lee, J. Mater. Sci. 26 (1991) 4961-4965

[15] E.L. Illekova, I. Matko, P. Duhaj, J. Mater. Sci. 32 (1997) 4645-4654

[16] M. Imafuku, S. Sato, H. Koshiba, E. Matsubara, A. Inoue, Scripta Mater. 44 (2001) 2369-2372

[17] O. V. Ogorodnikova, J. Roth, M. Mayer, J. Appl. Phys. 103 (2008) 034902

[18] B.S. Li, Y.Y. Du, Z.G. Wang, T.L. Shen, Y.F. Li, C.F. Yao, J.R. Sun, M.H. Cui, K.F. Wei, H.P. Zhang, Y.B. Shen, Y.B. Zhu, L.L. Pang, Nucl. Instrum. Methods Phys. Res., Sect. B 337 (2014) $21-26$ 
[19] J. Grisolia, A. Claverie, G. Ben Assayag, S. Godey, E. Ntsoenzok, F. Labhom, A. Van Veen, J. Appl. Phys. 91 (2002) 9027

[20] B. Wang, X.X. Mei , H.R. Zhang, W.J. Hou, Y.N. Wang, Z.G. Wang, C. Dong, J. Nucl. Mater. 444 (2014) 342-348

[21] J.L. Brimhall, J. Mater. Sci. 19 (1984) 1818-1826

[22] A. Inoue, Acta. Mater. 48 (2000) 279-306.

[23] C. Su, Y. Chen, P. Yu, M. Song, W. Chen, S.F. Guo, J. Alloy. Compd. 663 (2016) 867-871

[24] H. C. Chen, G. Q. Cao, R. D. Liu, G. Wang, L. Yan, X. T. Zhou, J. Appl. Phys. 118 (2015) 035308

[25] Z. Hu, Z.Q. Zhao, Y.D. Wu, T. Lu, J.S. Xing, B.C. Wei, Vacuum. 89 (2013) 142-146 


\section{Figures captions:}

Fig.1. XRD patterns of metallic glasses $\mathrm{Fe}_{80} \mathrm{Si}_{7.43} \mathrm{~B}_{12.57}$ irradiated by $\mathrm{He}$ ions of $300 \mathrm{keV}$ with different fluences.

Fig.2. (a)The cross-section TEM image (b)the corresponding SAED pattern of pristine metallic glass $\mathrm{Fe}_{80} \mathrm{Si}_{7.43} \mathrm{~B}_{12.57}$.

Fig.3. (a)The cross-section TEM image (b)the corresponding SAED pattern of none- He bubbles layer A within (a) (c)the corresponding SAED pattern of He bubbles layer B within (a) (d)the corresponding SAED pattern of outside ion range region $\mathrm{C}$ within (a) of metallic glass Fe ${ }_{80} \mathrm{Si}_{7.43} \mathrm{~B}_{12.57}$ irradiated by He ions up to a fluence of $4 \times 10^{17}$ ions $/ \mathrm{cm}^{2}$.

Fig.4. The HRTEM images of different crystallization areas (a) $\beta$-Mn type([521]) phase shows in the white box (b) the corresponding FFT pattern of the white box in (a) (c) $\beta$-Mn type([421]) phase shows in the white box (d) the corresponding FFT pattern of the white box in (c) in the He bubbles layer of metallic glass $\mathrm{Fe}_{80} \mathrm{Si}_{7.43} \mathrm{~B}_{12.57}$ irradiated by $\mathrm{He}$ ions up to a fluence of $4 \times 10^{17}$ ions $/ \mathrm{cm}^{2}$.

Fig.5. (a)The cross-section TEM image (b)the corresponding SAED pattern of none- He bubbles layer A within (a) (c)the corresponding SAED pattern of He bubbles layer B within (a) of metallic glass $\mathrm{Fe}_{80} \mathrm{Si}_{7.43} \mathrm{~B}_{12.57}$ irradiated by He ions up to a fluence of $1 \times 10^{18}$ ions $/ \mathrm{cm}^{2}$.

Fig.6. The HRTEM images of different crystallization areas (a) $\alpha-F e$ phase([111]) shows in the white box (b) the corresponding FFT pattern of the white box in (a) (c) $\mathrm{Fe}_{2} \mathrm{~B}$ phase([102]) shows in the white box (d) the corresponding FFT pattern of the white box in (c) in the He bubbles layer of metallic glass $\mathrm{Fe}_{80} \mathrm{Si}_{7.43} \mathrm{~B}_{12.57}$ irradiated by $\mathrm{He}$ ions up to a fluence of $1 \times 10^{18}$ ions $/ \mathrm{cm}^{2}$.

Fig.7. (a)The cross-section TEM image (b)the corresponding SAED pattern of none- He bubbles layer A within (a) (c)the corresponding SAED pattern of He bubbles layer B within (a) of metallic glass $\mathrm{Fe}_{80} \mathrm{Si}_{7.43} \mathrm{~B}_{12.57}$ irradiated by He ions up to a fluence of $1.6 \times 10^{18}$ ions $/ \mathrm{cm}^{2}$.

Fig.8. The HRTEM images of different crystallization areas (a) white box A : $\alpha$-Fe phase([100]); white box B : $\beta$-Mn type phase([421]); white box $\mathrm{C}: \mathrm{Fe}_{2} \mathrm{~B}$ phase([102]) (b) the corresponding FFT pattern of the white box A in (a) (c) the corresponding FFT pattern of the white box B in (a) (d) the corresponding FFT pattern of the white box $\mathrm{C}$ in (a) (e) white box $\mathrm{A}$ : $\mathrm{Fe}_{3} \mathrm{~B}$ phase ([432]) (f) the corresponding FFT pattern of the white box in (e) in the He bubbles layer of the metallic glass (g)the distribution of composition with depth in metallic glass $\mathrm{Fe}_{80} \mathrm{Si}_{7.43} \mathrm{~B}_{12.57}$ irradiated by He ions up to a fluence of $1.6 \times 10^{18}$ ions $/ \mathrm{cm}^{2}$.

Fig.9. The HRTEM image of He bubbles layer in $\mathrm{Fe}_{80} \mathrm{Si}_{7.43} \mathrm{~B}_{12.57}$ metallic glasses irradiated by He ions with different fluences (a) $4 \times 10^{17}$ ions $/ \mathrm{cm}^{2}$ (b) $1 \times 10^{18}$ ions $/ \mathrm{cm}^{2}$ (c) $1.6 \times 10^{18}$ ions $/ \mathrm{cm}^{2}$

Fig.10. The TEM image of (a)the under-focus and (b)the over-focus of He bubbles layer (c)the 
connection and growth of He bubbles (d)the crystallization in He bubbles layer of metallic glass $\mathrm{Fe}_{80} \mathrm{Si}_{7.43} \mathrm{~B}_{12.57}$ irradiated by $300 \mathrm{keV}$ He ions up to a fluence of $1.6 \times 10^{18}{ }_{\text {ions }} / \mathrm{cm}^{2}$.

Fig.11. XRD patterns of metallic glasses $\mathrm{Fe}_{68} \mathrm{Zr}_{7} \mathrm{~B}_{25}$ irradiated by He ions of $300 \mathrm{keV}$ with different fluences.

Fig.12. (a)The cross-section TEM image (b)the corresponding SAED pattern of He bubbles layer A within (a) (c)the corresponding SAED pattern of none-He bubbles layer B within (a) of metallic glass $\mathrm{Fe}_{68} \mathrm{Zr}_{7} \mathrm{~B}_{25}$ irradiated by $\mathrm{He}$ ions up to a fluence of $1.6 \times 10^{18}{ }^{\mathrm{ions}} / \mathrm{cm}^{2}$.

Fig.13. The TEM image of (a) the under-focus and (b)the over-focus of He bubbles layer in the metallic glass $\mathrm{Fe}_{68} \mathrm{Zr}_{7} \mathrm{~B}_{25}$ irradiated by $\mathrm{He}$ ions up to a fluence of $1.6 \times 10^{18}$ ions $/ \mathrm{cm}^{2}$.

Fig.14. The SEM images of (a0)-(a3) metallic glasses Fe ${ }_{80} \mathrm{Si}_{7.43} \mathrm{~B}_{12.57}\left(\mathrm{~b}_{0}\right)-\left(\mathrm{b}_{3}\right)$ metallic glasses $\mathrm{Fe}_{68} \mathrm{Zr}_{7} \mathrm{~B}_{25}\left(\mathrm{c}_{0}\right)-\left(\mathrm{c}_{3}\right)$ tungsten before and after irradiation by He ions with different fluences.

Fig.15. The SEM images of (a) shear steps in the exfoliation on the surface of metallic glass $\mathrm{Fe}_{80} \mathrm{Si}_{7.43} \mathrm{~B}_{12.57}$ (b) exfoliation on the surface of metallic glass $\mathrm{Fe}_{68} \mathrm{Zr}_{7} \mathrm{~B}_{25}$ irradiated by $\mathrm{He}$ ions up to a fluence of $1.6 \times 10^{18}$ ions $/ \mathrm{cm}^{2}$ 


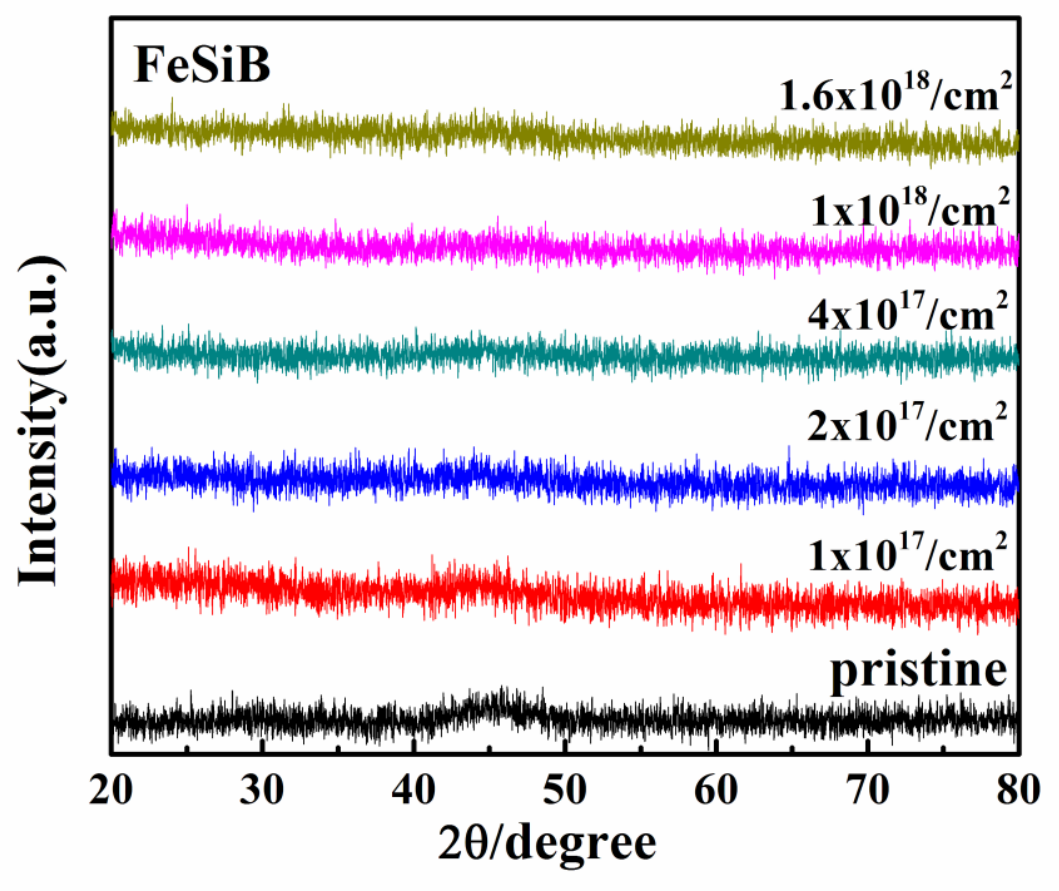

Fig.1 


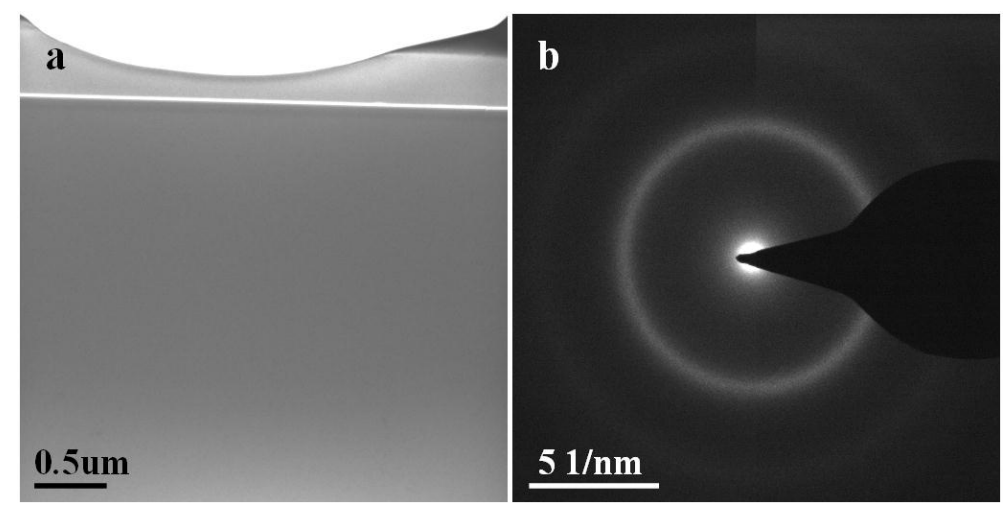

Fig. 2 


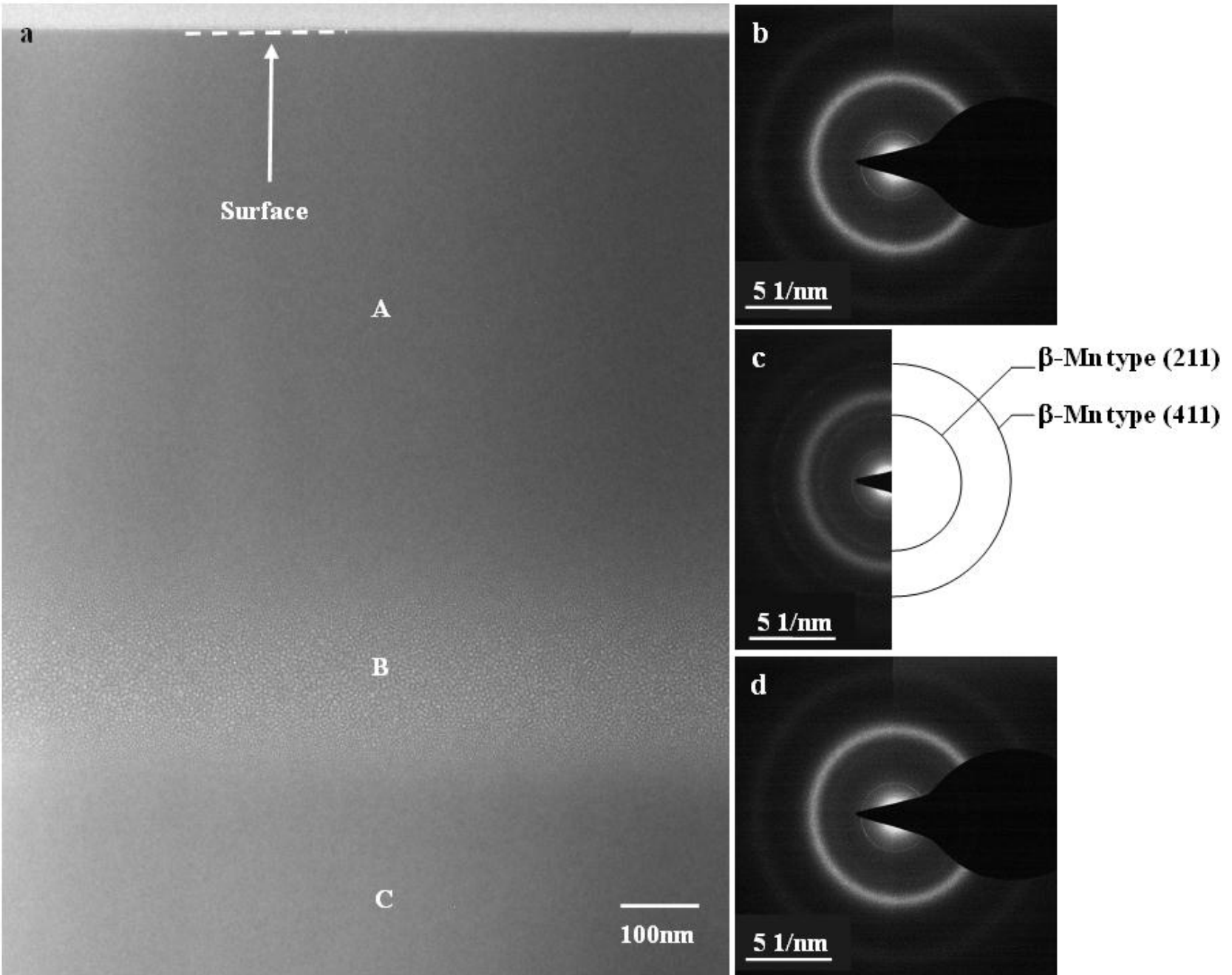

Fig.3 


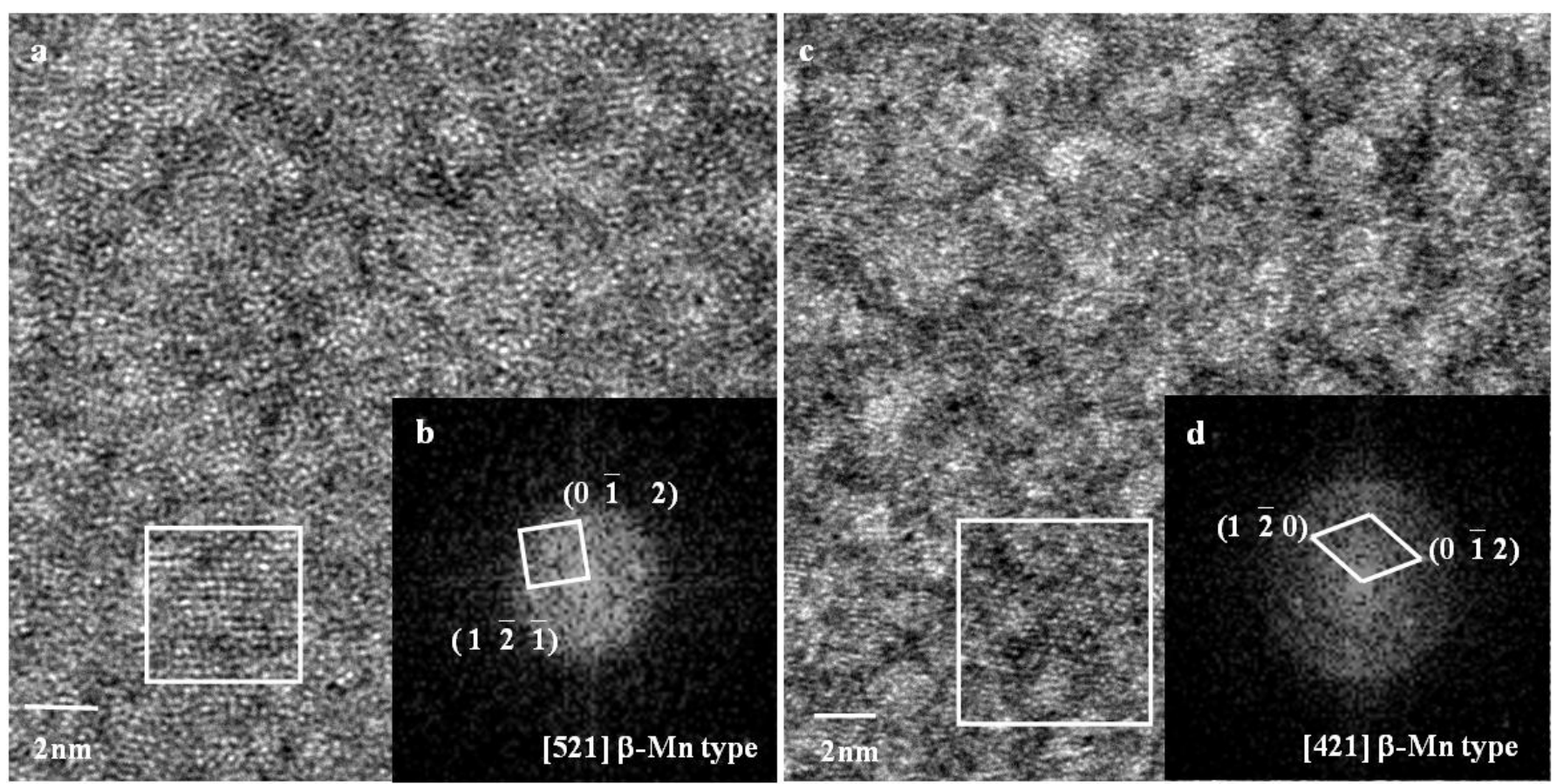

Fig.4 

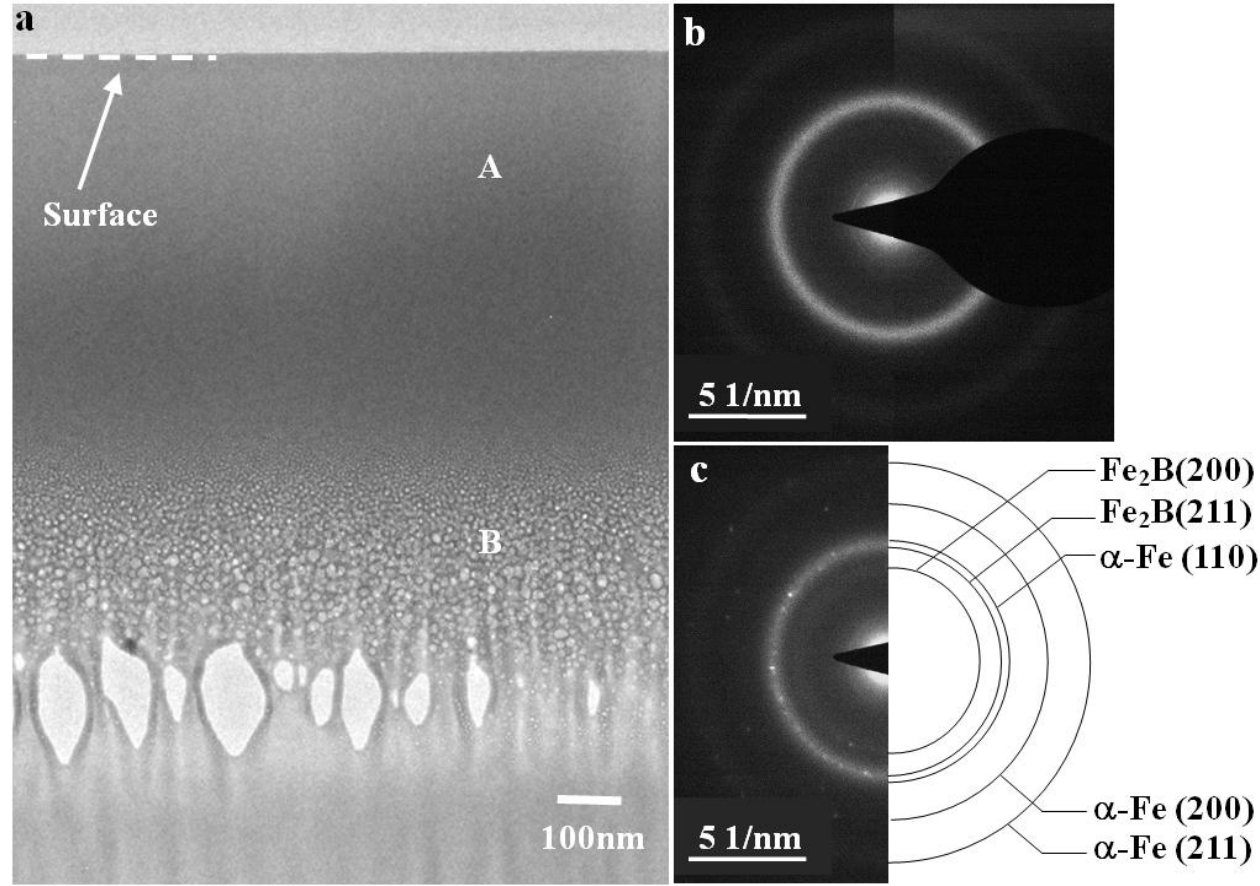

Fig. 5 

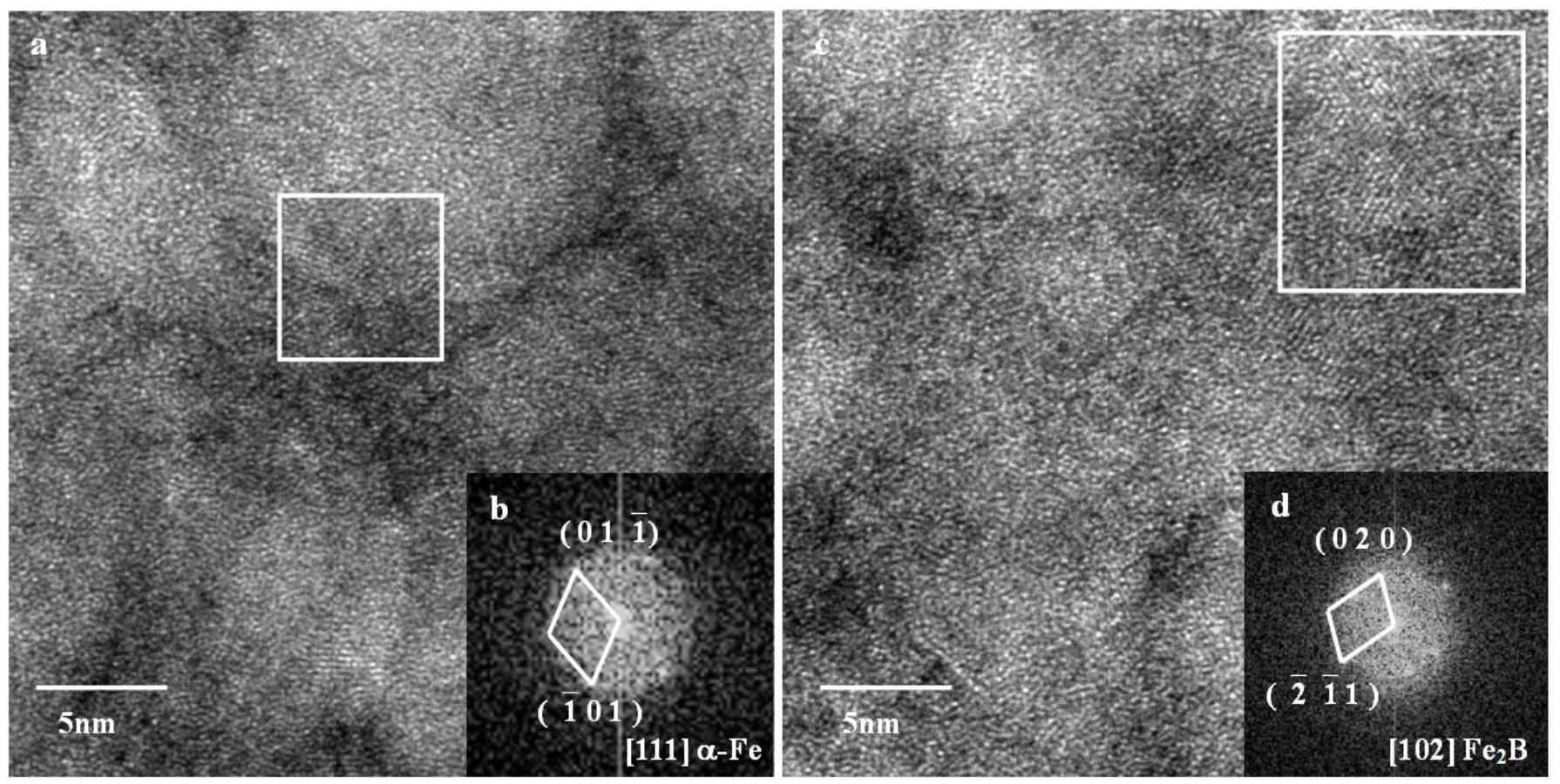

Fig.6 

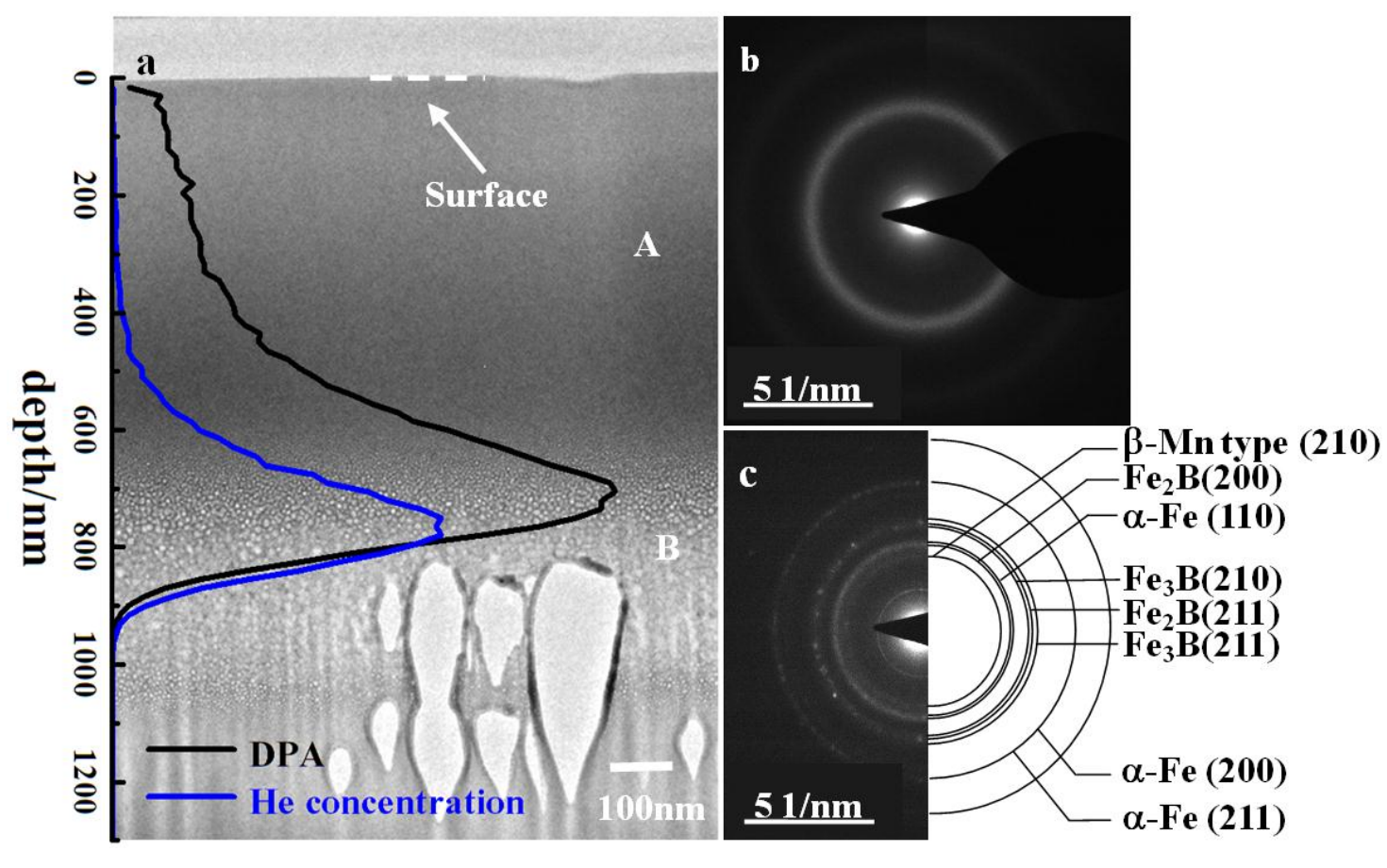

Fig.7 

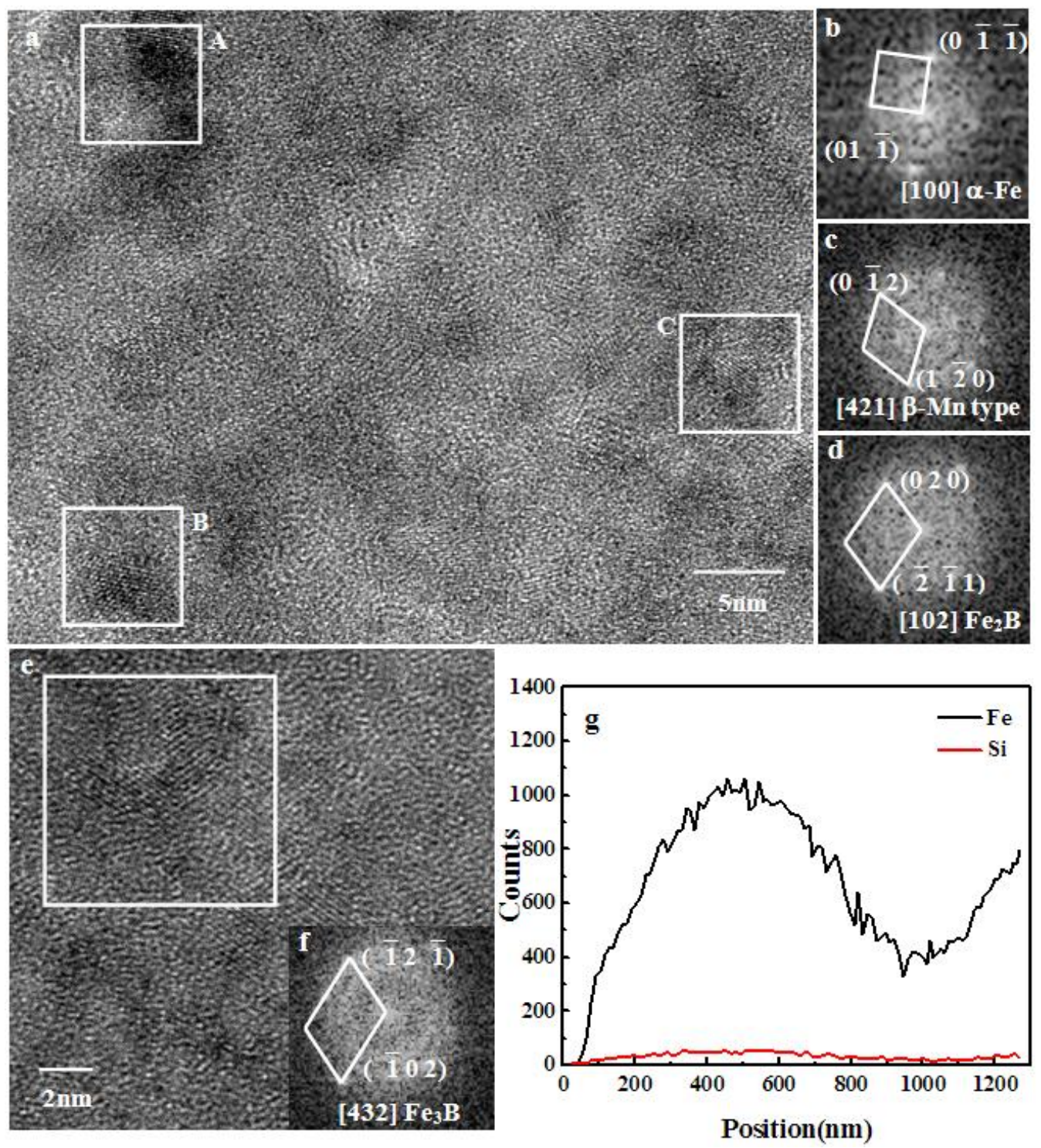

Fig.8 




Fig.9 

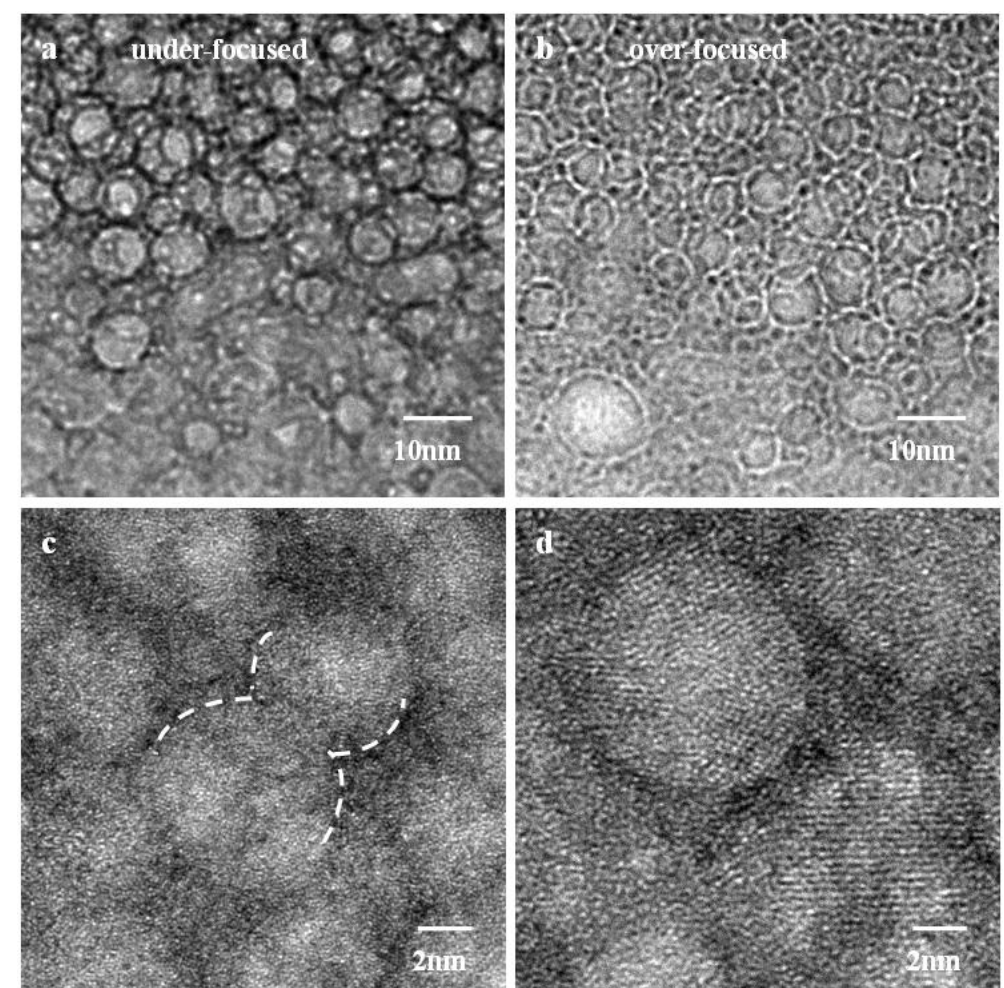

Fig.10 


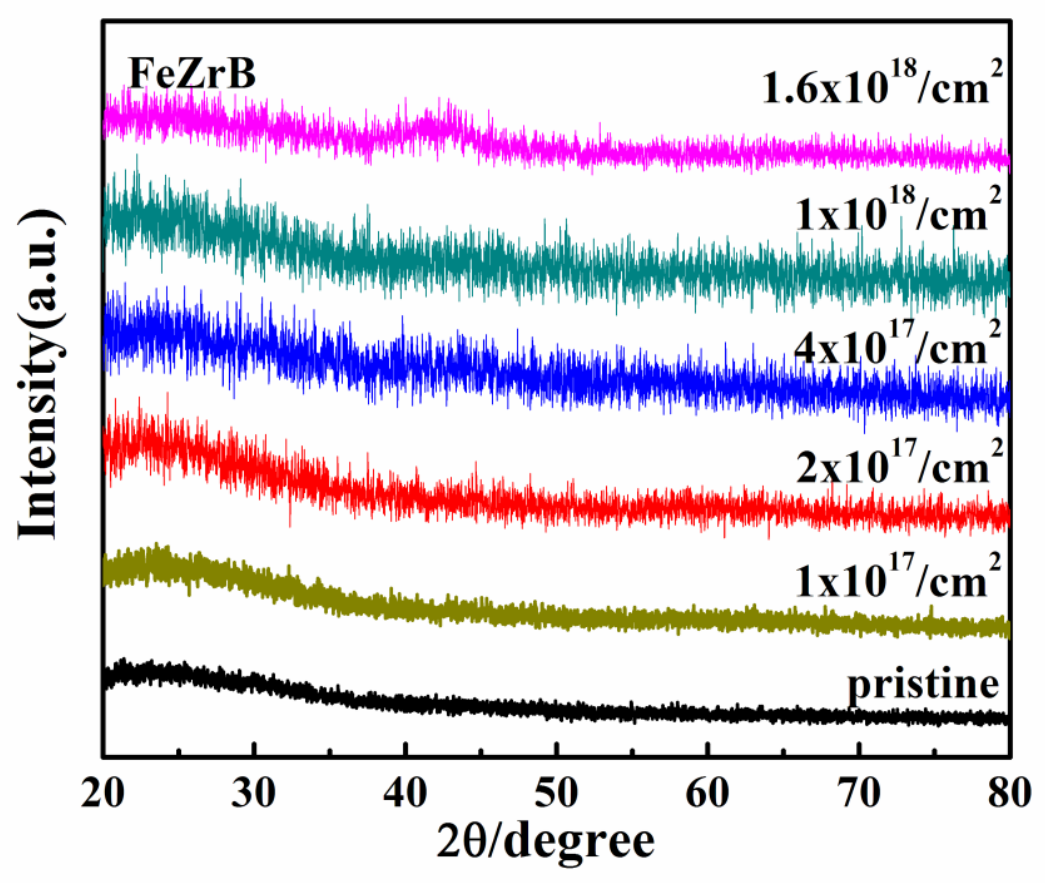

Fig.11 


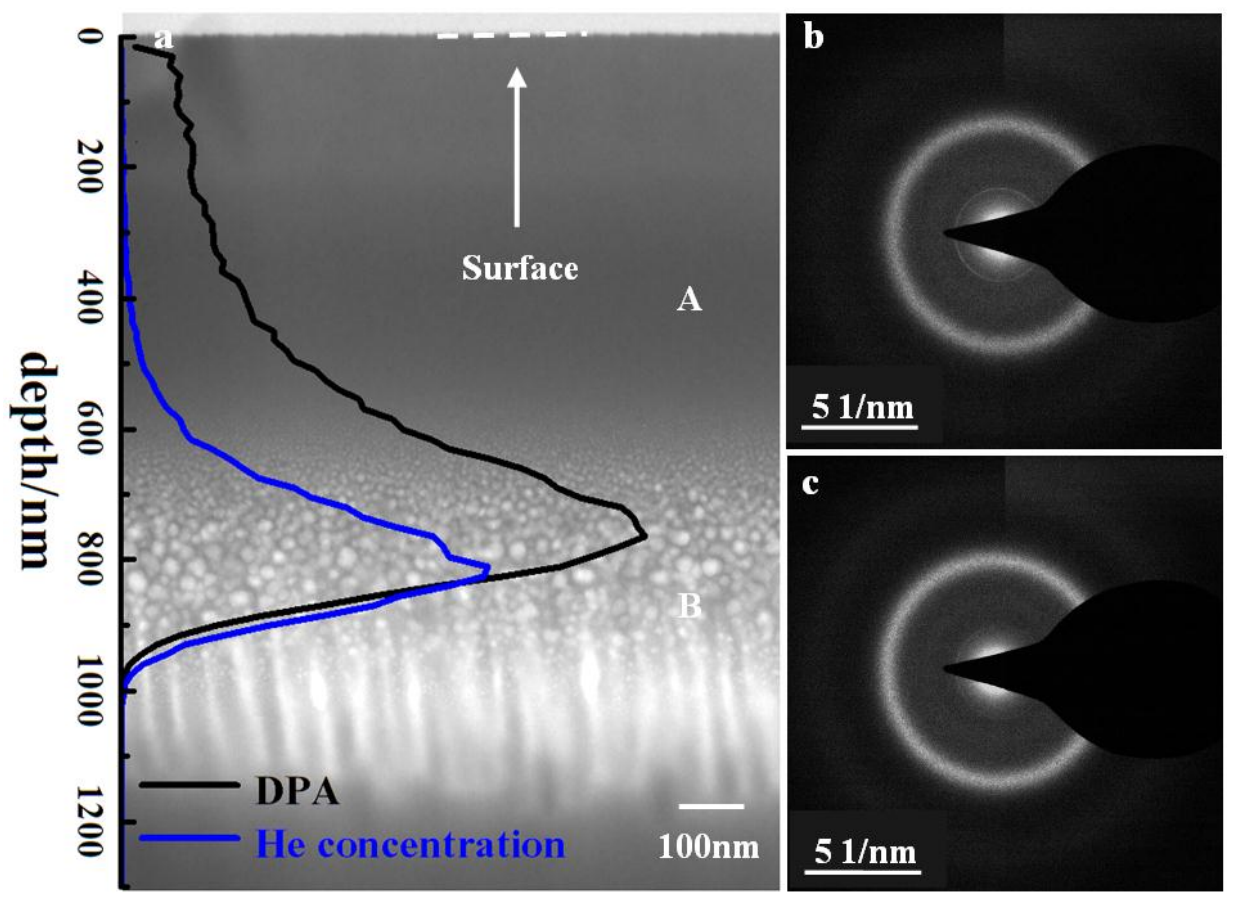

Fig. 12 


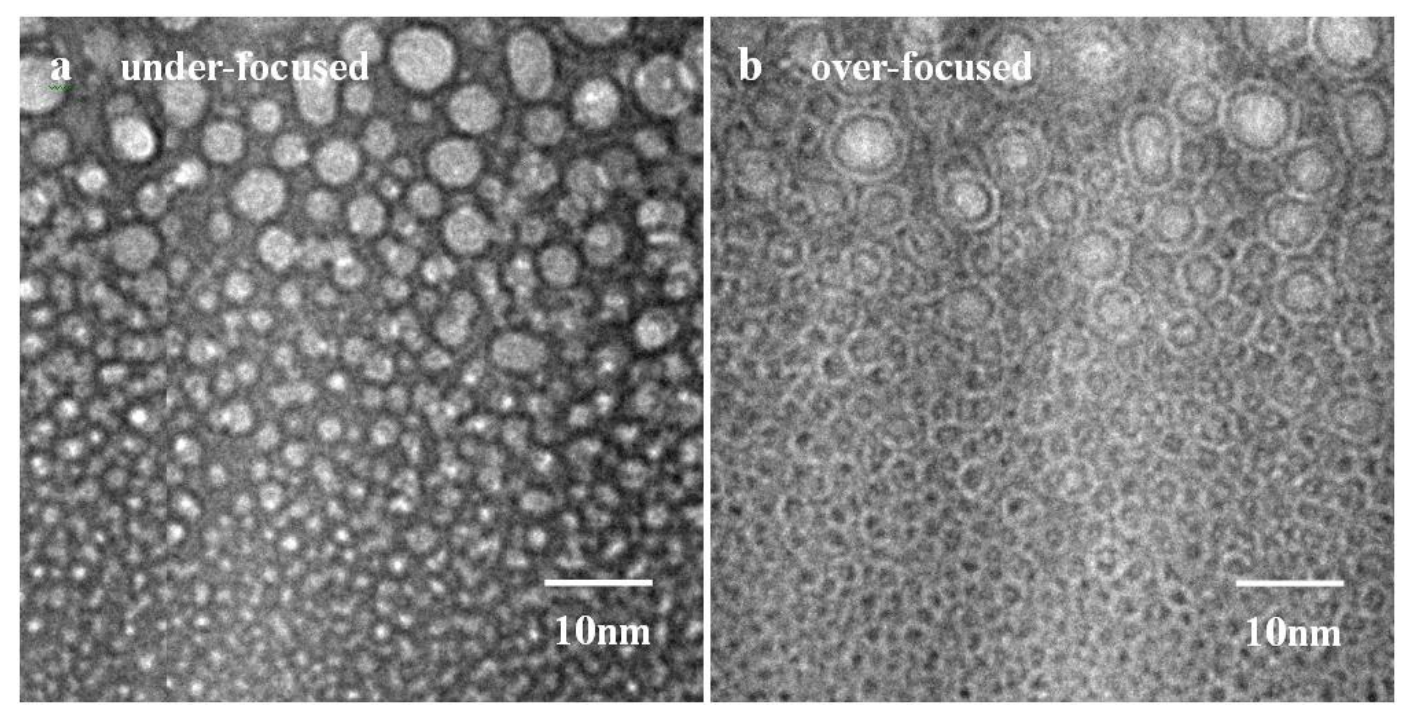

Fig.13 

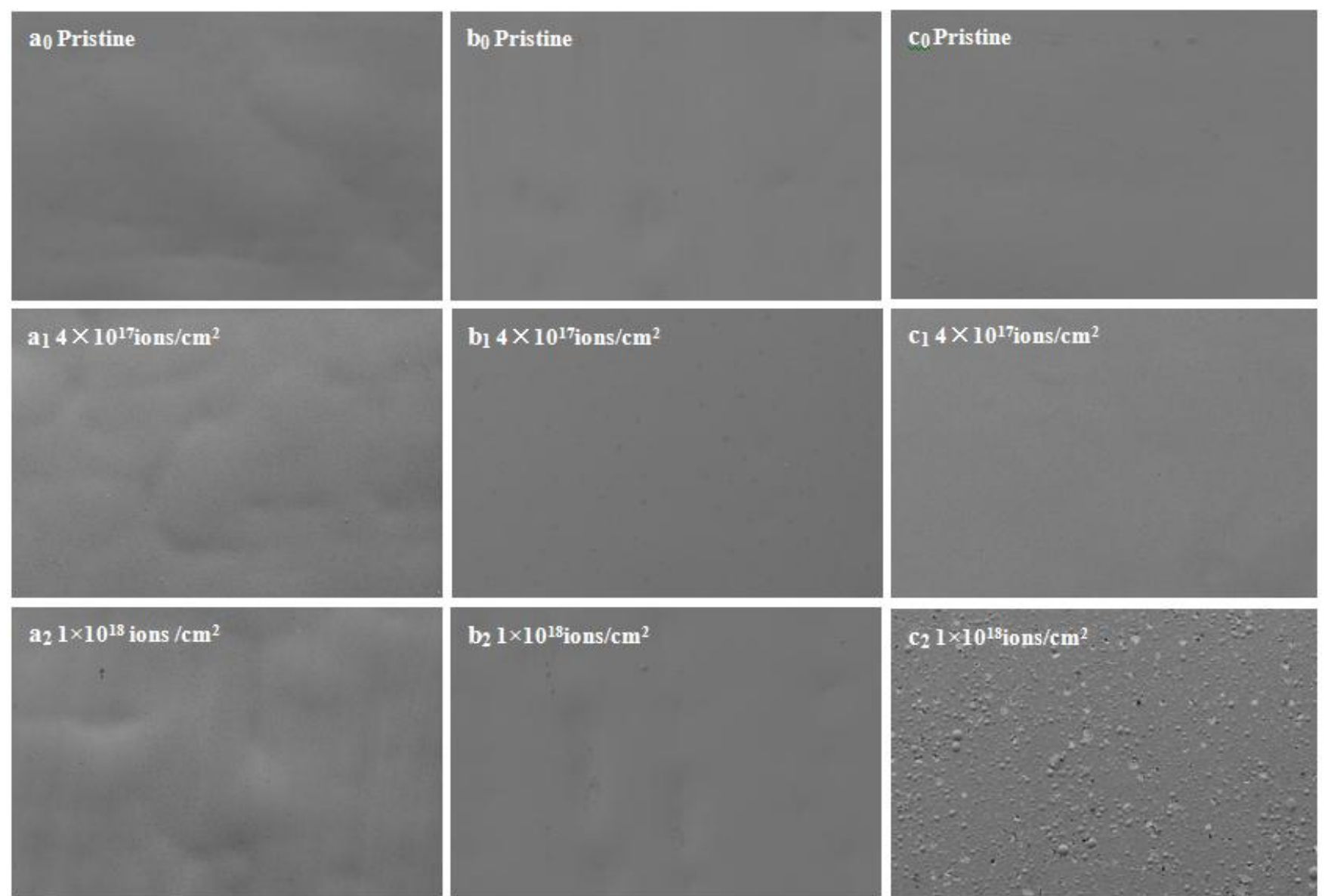

$b_{2} 1 \times 10^{18_{\text {ions }} / \mathrm{cm}^{2}}$
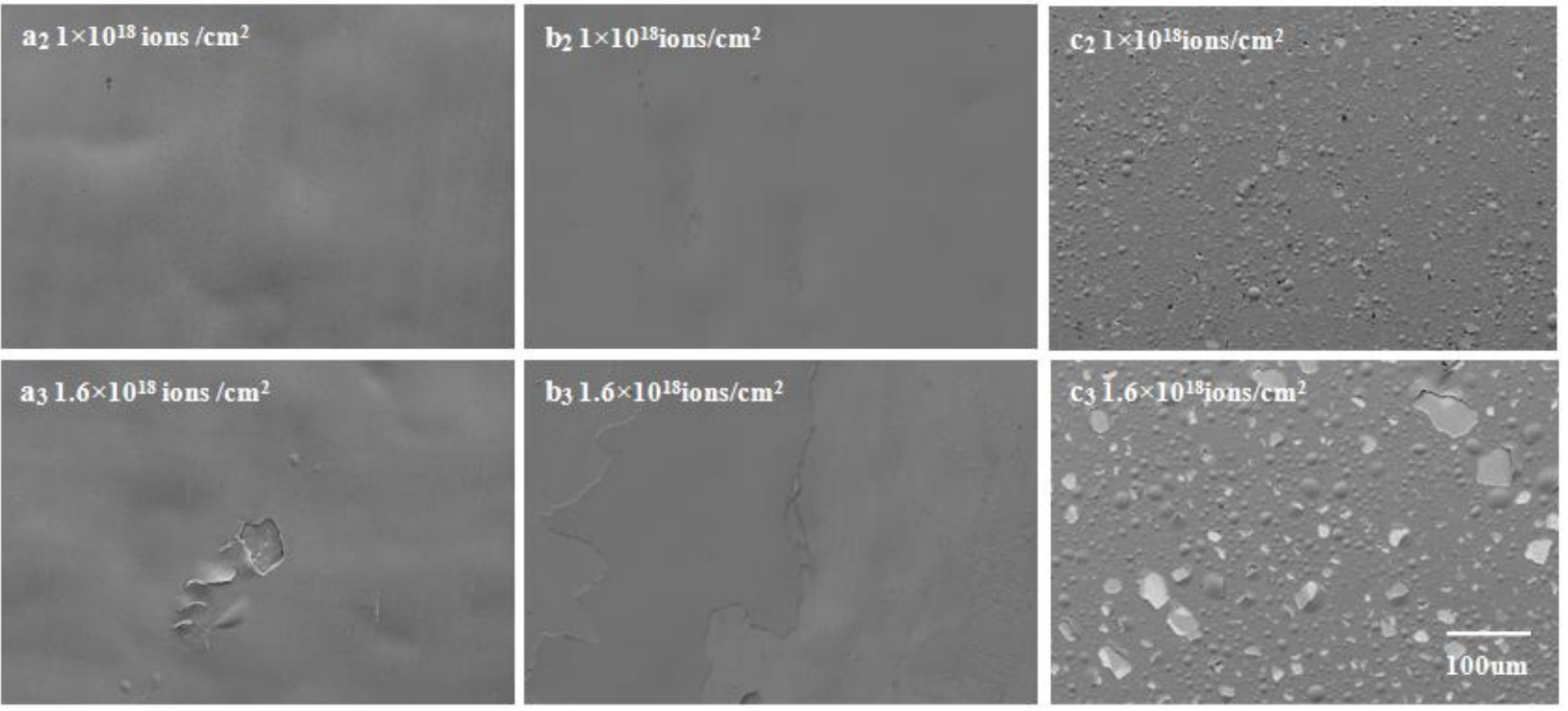

Fig.14 



Fig.15 